\title{
Synthesis of Polyacethylenes and Polysaccharides by Mushroom Ganoderma Lucidum (Curtis) P. Karst and Pleurotus Ostreatus (Jacq.) P. Kumm
}

\author{
Konul Farukh Bahshaliyeva1,2, Nizami Rza Namazov1,3, Arzu Rasul Hasanova1,3, \\ Sevinch Chamaladdin Garayeva ${ }^{1}$, Sevil Ehtibar Nagiyeva ${ }^{1}$ \\ ${ }^{1}$ Institute of Microbiology, National Academy of Sciences of Azerbaijan, Baku, Azerbaijan \\ ${ }^{2}$ Institute of Fruit and Tea-Making of the Ministry of Agriculture of the Republic of Azerbaijan, Kuba, Azerbaijan \\ ${ }^{3}$ Sumkayit State University, Sumkayit, Azerbayijan \\ Email:mpanah@mail.ru
}

How to cite this paper: Bahshaliyeva, K.F., Namazov, N.R., Hasanova, A.R., Garayeva, S.C. and Nagiyeva, S.E. (2019) Synthesis of Polyacethylenes and Polysaccharides by Mushroom Ganoderma Lucidum (Curtis) P. Karst and Pleurotus Ostreatus (Jacq.) P. Kumm. Advances in Bioscience and Biotechnology, 10, 226-232.

https://doi.org/10.4236/abb.2019.108017

Received: July 4, 2019

Accepted: August 25, 2019

Published: August 28, 2019

Copyright $\odot 2019$ by author(s) and Scientific Research Publishing Inc. This work is licensed under the Creative Commons Attribution International License (CC BY 4.0).

http://creativecommons.org/licenses/by/4.0/

\begin{abstract}
The purpose of the present work was to study the biosynthesis of various compounds of basidial xylotrophic mushroom Ganoderma lucidum and Pleurotus ostreatus, which were taken to the pure culture from the fruit body of the mushroom living on hornbeam and beech. Shown, that mushroom can synthesize various substances, which composed includes fractions differing in functionality. Among the found fractions, one relates to the polyacetylene (PA), which are characterized by a high degree of unsaturation, contain many double and triple bonds, and are well absorbed in the ultraviolet range.
\end{abstract}

\section{Keywords}

Fungi, Biosynthesis, Subfractions, Polyacethylenes, Polysaccharides, Structure, Chromatographic Condition

\section{Introduction}

One of the strategic directions for development of biologically active substances is targeted synthesis of natural compound [1] [2] or their synthetic analogues, and of these natural polyacetylen compounds are the main ones [3].

The development of new methods for the synthesis of natural polyacetylene compounds by chemical and microbiological methods [1] opens big perspective for their use in the targeted synthesis of practically valuable substances, which are actual. 
Now, studies in this direction continue to attract attention of a wide number of researchers, chemists-organists, bioorganists and chemists, as well as different profile biologists [2] [4]. From scientific and applied approaches, this direction is perspective one. Therefore, the development of effective methods of polyacetylen compounds synthesis [5] based on available raw products is an actual task.

It's known that basidomycetes are the source of the whole line of biologically active compounds proteins, lipids, polysaccharide, organic acids, enzymes, vitamins and etc., most of which are biologically active substances and compared to the chemical synthesis products are less toxic and more effective ones [6] [7] [8] [9]. The most expressed ones among them are Polysaccharides (PS) [10] [11] [12] and Polyaccetylens (PA) [5], and the last one consists of a lot of reactions able conjugated double and triple bonds. Use basidomycets as a source of PA compounds and PS is a very perspective way, because it gives a chance for their further use to obtain biologically active drugs, which can be used in medicine [13] [14] [15].

Due to widespread of basidial fungi in Azerbaijan [16], the purpose of this work is studying the biosynthesis of polyacetylen compounds by basidial fungi Ganoderma lucidum and Pleurotus ostreatus.

\section{Materials and Methods}

During the work, xylothrophic basidial fungi Ganoderma lucidum and Pleurotus ostreatus were used. They were distinguished into the pure culture from the fruit bodies of fungi located on hornbeam and beech, in forest ecosystems of Azerbaijan Republic.

Fungi were grown by method of deep cultivation in glucose-peptone medium under $28^{\circ} \mathrm{C}$. Biomass of fungi formed in 7 days, was separated from cultural fluid, crumbled up and extracted by water and acetic acid ethyl ether. Received extracts were analyzed by different methods.

IR specters of synthesized compounds, were taken by spectrometer UR_20 on 400-400 sm-1 range with thin layer. Specters of NMR $1 \mathrm{H}$ were recorded by devise "Tesla BS-487 B" (80MHz). As an inner standard hexamethyl disiloxan was used, solvent-CCl4. Chromatographic researches were conducted on high effective fluid chromatograph made by "Kovo" company (Czech). Double detector options of exclusion (ECF) and reverse faze absorb fluid chromatography (RFAFC) were used. Detectors: refractometer and UV spectrophotometer (254 $\mathrm{nm})$. Column with size $3.3 \times 150 \mathrm{~mm}$ filled by absorbents "Separon SGX" (EFC) with porosity 100 A and "Separon SGX C-18" with reverse faze (RFAFC) with size of particles $7 \mathrm{~m} \cdot \mathrm{km}$ was used. Eluents-dimethylmformamide and acetonitril $+\mathrm{H}_{2} \mathrm{O}(75+25 \mathrm{vol} \%)$ consistently, speed of giving $0.3 \mathrm{ml} / \mathrm{min} . \mathrm{T}=20^{\circ} \mathrm{C}-25^{\circ} \mathrm{C}$. Parametres of molecule-mass spread (MMS) was detected by EFC method [17].

\section{Results and Discussions}

Results of EFC and RFAFC researches on water and ether extracts received after processing of biomass of correspondent basidial fungi (Ganoderma lucidum and 
Pleurotus ostreatus) were introduced in Table 1 and Figure 1 and Figure 2.

It was identified that there is a big similarity between results received in case of signed types of fungi. In both cases by characters of RFAFC chromatograms it is possible to consider that analyzed products consist of mix of fractions of two different types of compounds. As the first fraction was fixed simultaneously either by refract meter (curve $a$ and $a^{I}$, picks 1 ) and by UV detector with multiplet character of 5 maximums and different intensities (curve b picks 1 - 5). This testifies about existence of 5 subrfractions of different functionalities, well absorbed in UV range. Individual character of fractions signal by refrectmeter associated with affinity of physical chemical parameters, especially optic density of compounds in its structure. As a result of physical-chemical analyses it was identified their applicability to polyacetylene compounds of high level of unsaturation with a lot of triple and double bonds i.e. active chromophore groups absorbed in UF area. The remaining 4 fractions are fixed only by refractometry and belong to well water-soluble polysaccharides (PS) with main function groups (auxochromous hydroxyl groups), which are not absorbed in UV range (curve a).

By the characters of chromatographs, it is obvious that as it is expected in the ether extracts quantitatively prevail PA (curve a), but in water extracts PS (curve a). In both cases, quantity of PA and PS received from biomass of correspondent

Table 1. Mass molecular characteristics of PA received as a result of biosynthesis by basidiomycetes Ganoderma lucidum (fraction 1 - 7) and Pleurotus ostreatus (fraction 7 14) $\mathrm{V}_{\mathrm{R}}=\mathrm{C}_{1}-\mathrm{C}_{2} \lg \mathrm{M}, \mathrm{C}_{1}=24.4, \mathrm{C}_{2}=4.0$.

\begin{tabular}{|c|c|c|c|c|c|c|c|c|}
\hline \multirow{2}{*}{$\begin{array}{c}\text { Frac-tions } \\
\text { № }\end{array}$} & \multirow{2}{*}{$\begin{array}{c}\text { Fraction } \\
\text { name }\end{array}$} & \multicolumn{2}{|c|}{$\begin{array}{l}\text { Content of } \\
\text { fractions, } \%\end{array}$} & \multicolumn{2}{|c|}{$\begin{array}{l}\text { Content of } \\
\text { fractions, } \%\end{array}$} & \multirow{2}{*}{$M_{w} / M_{n}$} & \multirow{2}{*}{$\begin{array}{r}V_{R} \\
\max \end{array}$} & \multirow{2}{*}{$\begin{array}{c}\mathrm{MM} \\
V_{R} \\
\max \end{array}$} \\
\hline & & $\begin{array}{c}\text { In methyl } \\
\text { ether }\end{array}$ & $\begin{array}{c}\text { In } \\
\text { water }\end{array}$ & $M_{W}$ & $M_{n}$ & & & \\
\hline 1 & PA & 74 & 6.0 & 180 & 180 & 1.0 & 1 & 180 \\
\hline 2 & Geksaoza & 11 & 42.5 & 1085 & 1085 & 1.0 & 2 & 1085 \\
\hline 3 & Geptaoza & 18 & 31 & 1260 & 1260 & 1.0 & 3 & 1260 \\
\hline 4 & Oligosaccharide & 3.0 & 11.5 & 4390 & 3600 & 1.22 & 4 & 2430 \\
\hline 5 & Oligosaccharide & 4.0 & 10 & 5450 & 4500 & 1.21 & 5 & 4730 \\
\hline 6 & --- & - & - & 1912 & 1260 & 1.82 & 6 & - \\
\hline 7 & --- & - & - & 829 & 229 & 3.62 & 7 & - \\
\hline 8 & PA & 71 & 8.0 & 180 & 180 & 1.0 & 8 & 180 \\
\hline 9 & Geksaoza & 12 & 40 & 1085 & 1085 & 1.0 & 9 & 1085 \\
\hline 10 & Geptaoza & 7.0 & 33 & 1260 & 1260 & 1.0 & 10 & 1260 \\
\hline 11 & Oligosaccharide & 5.0 & 12 & 4600 & 3500 & 1.31 & 11 & 2985 \\
\hline 12 & Oligosaccharide & 5.0 & 7.0 & 5600 & 4650 & 1.2 & 12 & 4000 \\
\hline 13 & --- & - & - & 1806 & 893 & 2.02 & 13 & - \\
\hline 14 & --- & - & - & 855 & 244 & 3.5 & 14 & - \\
\hline
\end{tabular}




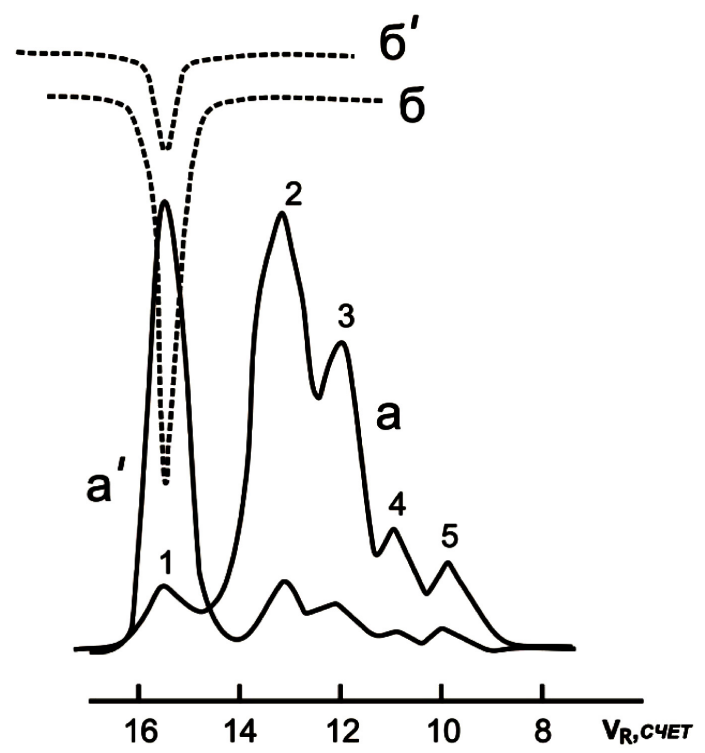

Figure 1. RFAFC curves of mix of PA and PS received during biosynthesis by basidial fungi type Ganoderma lucidum, allocated by extraction with methyl ether (curve a and b) Detectors refractometric (full line), UV-spectrophotometric (254 nm) (dashed line).

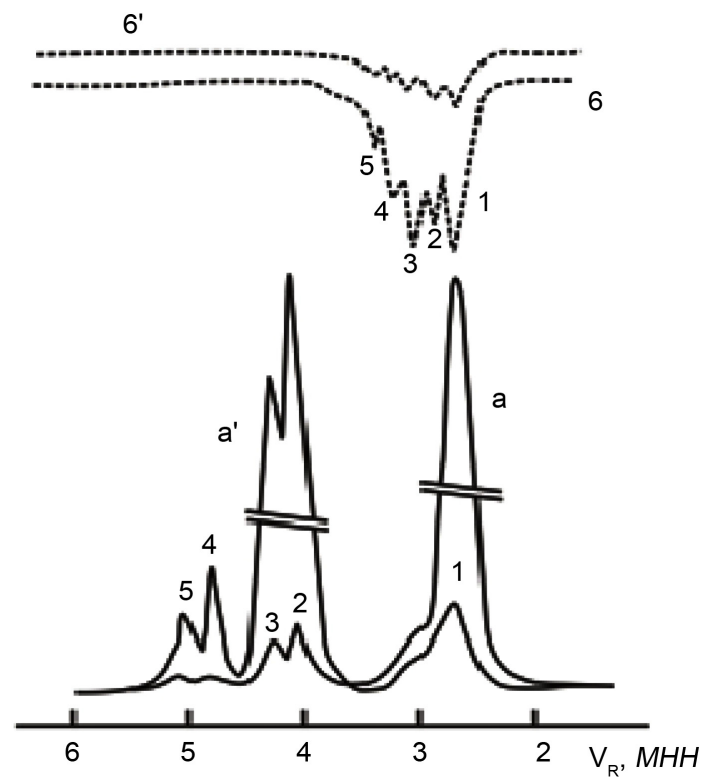

Figure 2. Curves of MMR mix of PA and PS taken by EFC mode distinguished during extraction by methyl ether (curve a and b) and water (curve a1 and b1). The detectors: refractometer (solid line), UVspectrophotometric (254 nm) (dashed line).

basidiomycetes reaches to $70 \%-80 \%$.

Investigation on MMS of extracts by EFC method allowed establishing proportion of each fraction in its composition. Optimal conditions to provide 
the maximal transition of PA and PC from cultural fluid to ME and water were identified. For example, content of PA in ME extract reaches to 70\% (Ganoderma lucidum), and quantity of oligosaccharides, in this case, reaches only to $10 \%$. In case of water extracts contrary was identified i.e. only $6 \%$ of PA fraction is fixed, but to $80 \%$ of fraction of PS with different values of $M_{n}$ (Table 1). Wherein polyacetylens identified by refractometer, as in case of RFAFC so in this mode of separation is characterized by narrow pick with maximum on $V_{R}=15.5$ appropriate to $M_{n}=180$ (Figure 2, curve a). EFC analyze also confirmed polymer structure of the next fractions. So picks 2 - 5 (Figure 2 curve a) on EFC chromatogram of researching extracts with maximums on $V_{R}=9.8$ and 10.2, applicable to polysaccharide with $M_{n}=4500$ and 3600 (10\% и $\left.11.5 \%\right)$, but on $V_{R}=$ 12 and 13 to oligosaccharides' fractions with $M_{n}=1260$ (heptaoza) (31\%) and 1080 (tetraoza) (41.5\%). As per data given in the table, the changes of indicated fractions MM in that wide diapazone, reflected in degree of polydispersity (DP). The total value of extracts DPME is quite high (3.62 and 3.5) (table, fraction 7 and 14) than water extracts (1.82. and 2.02.) (fraction 6 and 13). Investigated chromatographic system allows distinguishing fractions form extracts with value of DP of quite low interval 1.0 - 1.2. As per information in the table in both cases using basidiomycetes genus Ganoderma lucidum and Pleurotus ostreatus the identical patterns is observed, only a slightly difference in quantitate proportions of fractions in composition of tested extracts is recorded. That shows that under given conditions as expected the action mechanisms of tested basidial fungus of biomass cultivation are similar. Comparison of UV chromatograms taken in EFC and RFAFC modes shows that in the last case the selectivity of the system by functionality of PA compound is high. So multiplet signals of PA fraction fixed in case of RFAFC (Figure 1, curve b and b1) in EFC mode differs by monomodality (Figure 2, curve $b$ and $b^{1}$ ).

In order to study the chemical composition, detected fractions of PA were separated by preparative way. It was achieved in conditions of extract high concentration by fraction multiply collecting of corresponding picks of RFAFC, fixed by UV detector, which was later analyzed by the structural way. Because of the investigations on chemical composition and structure of PA mixes grown by basidial fungus, 5 known compounds with the next structures correspondent by picks 1 - 5 (Figure 1, Curve b) were identified. Indicated compounds were fixed sequentially in the following order:

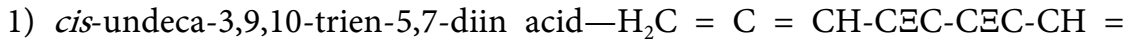
$\mathrm{CH}-\mathrm{CH}_{2}-\mathrm{COOH}$;

2) $c i s$-undec-2-ene-4,6,10-triin acid- $\mathrm{HC} \Xi \mathrm{C}-\mathrm{CH}_{2}-\mathrm{CH}_{2}-\mathrm{C} \Xi \mathrm{C}-\mathrm{C} \Xi \mathrm{C}-\mathrm{CH}=\mathrm{CH}_{2}$ $\mathrm{COOH}$;

3) $c i s$-non-4-ene-6,8-diin acid-HCEC-CEC-CH $=\mathrm{CH}-\mathrm{CH}_{2}-\mathrm{CH}_{2}-\mathrm{COOH}$;

4) $c i s$-undec-3-ene-5,7,10-triin-1-ol-HCEC- $\mathrm{CH}_{2}-\mathrm{C} \Xi \mathrm{C}-\mathrm{C} \Xi \mathrm{C}$ - $\mathrm{CH}=\mathrm{CH}-\mathrm{CH}_{2}$ $\mathrm{CH}_{2} \mathrm{OH}$;

5) deca-cis-2-trans-8-dien-4,6-diin-1-ol- $\mathrm{CH}_{3}-\mathrm{CH}=\mathrm{CH}-\mathrm{C} \Xi \mathrm{C}-\mathrm{C} \Xi \mathrm{C}-\mathrm{CH}=$ 


\section{$\mathrm{CH}-\mathrm{CH}_{2} \mathrm{OH}$.}

Thus, the results of researches on the process of biosynthesis identify opportunities of tested fungus to synthesize PA and PS, which can be used for medical purposes. In addition to that, the developed chromatographic condition allows controlling the cultivation conditions, consistently over the composition and structure of the biosynthesis products.

\section{Conflicts of Interest}

The authors declare no conflicts of interest regarding the publication of this paper.

\section{References}

[1] Debbab, A., Aly, A.H., Lin, W.H. and Proksch, P. (2010) Bioactive Compounds from Marine Bacteria and Fungi. Microbial Biotechnology, 3, 544-563. https://doi.org/10.1111/j.1751-7915.2010.00179.x

[2] Gal, Y.-S., Jin, S.-H., Lyoo, W.S., Park, J.-W. and Lim, K.T. (2011) Synthesis and Characterization of a Polyacetylene Derivative with Phenylazobenzene Moieties. Journal of Nanoscience and Nanotechnology, 11, 7386-7389. https://doi.org/10.1166/jnn.2011.4802

[3] Dembitsky, Y.M. (2006) Anticancer Activity of Natural and Synthetic Acetylenic Lipids. Lipids, 41, 883-924. https://doi.org/10.1007/s11745-006-5044-3

[4] Wlizło, K., Polak, J. and Jarosz-Wilkołazka, A. (2017) Biologically Active Compounds and Methods of Their Removal through Biocatalysis. Postępy Biochemii, 63, 304-314.

[5] Toshio, M. (2016) Substituted Polyacetylenes: Synthesis, Properties, and Functions. Polymer Reviews, 57, 1-14. https://doi.org/10.1080/15583724.2016.1170701

[6] Chen, Y., Du, X., Zhang, Y., Liu, X. and Wang, X. (2017) Ultrasound Extraction Optimization, Structural Features, and Antioxidant Activity of Polysaccharides from Tricholoma matsutake. Journal of Zhejiang University-SCIENCE B, 18, 674-684. https://doi.org/10.1631/jzus.B1600239

[7] Lin, C.H., Chang, C.Y. and Lee, K.R. (2016) Cold-Water Extracts of Grifola frondosa and Its Purified Active Fraction Inhibit Hepatocellular Carcinoma in Vitro and in Vivo. Experimental Biology and Medicine, 241, 1374-1385. https://doi.org/10.1177/1535370216640149

[8] Li, W., Zhou, W., Kim, E.J., Shim, S.H., Kang, H.K. and Kim, Y.H. (2015) Isolation and Identification of Aromatic Compounds in Lion's Mane Mushroom and Their Anticancer Activities. Food Chemistry, 170, 336-342. https://doi.org/10.1016/j.foodchem.2014.08.078

[9] Vazirian, M., Faramarzi, M.A., Ebrahimi, S.E., et al. (2014) Antimicrobial Effect of the Lingzhi or Reishi Medicinal Mushroom, Ganoderma lucidum (Higher Basidiomycetes) and Its Main Compounds. International Journal of Medicinal $\mathrm{Mu}$ shrooms, 16, 77-84. https://doi.org/10.1615/IntJMedMushr.v16.i1.70

[10] Martínez-Montemayor, M.M., Ling, T., Suárez-Arroyo, I.J., Ortiz-Soto, G., Santiago-Negrón, C.L., et al. (2019) Identification of Biologically Active Ganoderma lucidum Compounds and Synthesis of Improved Derivatives that Confer Anti-Cancer Activities in Vitro. Frontiers in Pharmacology, 10, 115.

https://doi.org/10.3389/fphar.2019.00115 
[11] Su, C.H., Lai, M.N., Lin, C.C. and Ng, L.T. (2016) Comparative Characterization of Physicochemical Properties and Bioactivities of Polysaccharides from Selected Medicinal Mushrooms. Applied Microbiology and Biotechnology, 100, 4385-4393. https://doi.org/10.1007/s00253-015-7260-3

[12] Hou, Y., Ding, X., Hou, W., Song, B. and Yan, X. (2017) Structure Elucidation and Antitumor Activity of a New Polysaccharide from Maerkang Tricholoma matsutake. International Journal of Biological Sciences, 13, 935-948. https://doi.org/10.7150/ijbs.18953

[13] Jin, X., Ruiz Beguerie, J., Sze, D.M. and Chan, G.C. (2016) Ganoderma lucidum (Reishi Mushroom) for Cancer Treatment. Cochrane Database of Systematic Reviews, 4, CD007731. https://doi.org/10.1002/14651858.CD007731.pub3

[14] Ren, L., Perera, C. and Hemar, Y. (2012) Antitumor Activity of Mushroom Polysaccharides: A Review. Food \& Function, 3, 1118-1130.

https://doi.org/10.1039/c2fo10279j

[15] Silveira, M.L.L., Smiderle, F.R., Agostini, F., Pereira, E.M., Bonatti-Chaves, M., Wisbeck, E., Ruthes, A.C., Sassaki, G.L., Cipriani, T.R., Furlan, S.A., et al. (2015) Exopolysaccharide Produced by Pleurotus sajor-caju: Its Chemical Structure and Anti-Inflammatory Activity. International Journal of Biological Macromolecules, 75, 90-96. https://doi.org/10.1016/j.ijbiomac.2015.01.023

[16] Ganbarov, K.G., Kulieva, N.A. and Muradov, P.Z. (2001) Biosynthesis of Pectinase by Fungi of the Genera Bjerkandera and Coriolus during Solid-Phase Fermentation. Applied Biochemistry and Microbiology, 37, 593-595. https://doi.org/10.1023/A:1012303101102

[17] Regnier, F.E. (1983) High-Performance Liquid Chromatography of Biopolimers. Science, 222, 245-252. https://doi.org/10.1126/science.6353575 